\title{
Alzheimer's disease: No effect of the CDK5 gene on CSF biomarkers, neuropathology or disease risk
}

\author{
ANNICA SJÖLANDER ${ }^{1}$, MALIN E. ANDERSSON ${ }^{1}$, HENRIK ZETTERBERG $^{1,2}$, LENNART MINTHON $^{3,4}$, \\ NENAD BOGDANOVIC ${ }^{5}$ and KAJ BLENNOW ${ }^{1}$
}

\author{
${ }^{1}$ Institute of Neuroscience and Physiology, Department of Neurochemistry and Psychiatry, \\ ${ }^{2}$ Institute of Biomedicine, Department of Clinical Chemistry and Transfusion Medicine, Sahlgrenska University Hospital, \\ Göteborg University, Göteborg; ${ }^{3}$ Clinical Memory Research Unit, Department of Clinical Sciences Malmö, Lund University; \\ ${ }^{4}$ Neuropsychiatric Clinic, Malmö University Hospital, Malmö; ${ }^{5}$ Neurotec Department, Section of Clinical Geriatrics, \\ Karolinska Institutet, Karolinska University Hospital in Huddinge, Stockholm, Sweden
}

Received April 4, 2009; Accepted June 4, 2009

DOI: $10.3892 / \mathrm{mmr} 00000203$

\begin{abstract}
Cyclin-dependent kinase 5 (cdk5) has been identified as one of the kinases that phosphorylates tau at several Alzheimer's disease (AD)-associated sites. Cdk5 is predominantly expressed in neurons, and has higher activity in $\mathrm{AD}$ brains than in non-demented brains. To investigate the effect of the $C D K 5$ gene on $\mathrm{AD}$, we analyzed an SNP of the $C D K 5$ gene (rs2069456) in 347 patients with AD and in 157 controls. $C D K 5$ genetic data was investigated in subgroups in relation to biochemical and neuropathological markers for AD. We found no significant differences in genotype or allele distributions between $\mathrm{AD}$ patients and controls. None of the CDK5 gene variants influenced biomarkers for AD.
\end{abstract}

\section{Introduction}

One of the characteristics of Alzheimer's disease (AD) is the intraneuronal accumulation of neurofibrillary tangles (NFTs). NFTs are composed of a hyperphosphorylated form of the microtubule-associated protein tau $(1,2)$. When tau is in its hyperphosphorylated form, its ability to perform the role of maintaining neuronal morphology by promoting the assembly and stabilization of microtubules is impaired (3). Cyclin-dependent kinase 5 (cdk5) is identified as one of the proline-directed serine/threonine kinases that mediates hyperphosphorylation at several AD-associated phosphorylation sites on tau (4-8). Cdk5 belongs to the cyclin-dependent

Correspondence to: $\mathrm{Dr}$ Annica Sjölander, Department of Clinical Chemistry and Transfusion Medicine, Molecular Biology, The Sahlgrenska Academy at Göteborg University, Sahlgrenska University Hospital, SE-413 45 Göteborg, Sweden

E-mail: annica.sjolander@neuro.gu.se

Key words: Alzheimer's disease, cyclin-dependent kinase 5, tau, $\beta$-amyloid, apolipoprotein E, cerebrospinal fluid, biomarkers, plaque, tangle kinase (cdk) family. However, in contrast to other cdks, cdk5 is not directly involved in cell cycle events (9). Although cdk5 is expressed in various tissues, its activity predominantly takes place in neurons as its activators, p35 and p39, are restricted to this cell type $(10,11)$. In the brain, cdk5 interacts closely with NFTs $(12,13)$. Significantly higher cdk5 activity is found in $\mathrm{AD}$ brains compared to non-demented brains (14). When the cysteine-protease calpain cleaves p35 into p25, a more stable p25-cdk5 complex is formed (15). This is due to the approximately 5-fold longer half-life of p25 compared to p35. Therefore, p25 can give rise to the prolonged activation of $\mathrm{cdk} 5$, which in turn leads to the hyperphosphorylation of tau (15). Of note, accumulations of both calpain and p25 are found in human AD brains (16).

Based on these findings, we hypothesized that the $C D K 5$ gene might be a candidate risk gene for AD. To test this hypothesis, we studied the influence of a single nucleotide polymorphism (SNP) in the CDK5 gene on the risk of AD and on biochemical and neuropathological markers. No previous study has investigated biochemical or neuropathological markers for AD in relation to $C D K 5$ genotype data. The rs2069456 SNP $(\mathrm{A} \rightarrow \mathrm{C}$, intron 7, http://genome.ucsc.edu) was selected due to its high allele frequency compared to other known SNPs in this gene. The global frequency of the least common variant $\mathrm{C}$ allele is reported to be 0.32 (http://www.ncbi.nlm.nih.gov/sites/entrez).

\section{Materials and methods}

Subjects. The study included a total of 347 patients with AD (120 men and 227 women) and 157 controls (73 men and 84 women) of Caucasian origin. Data on cerebrospinal fluid (CSF) levels of biochemical markers for AD were available for 265 AD patients ( $75 \pm 6.4$ years) and for 53 controls $(73 \pm 7.9$ years). Total-tau, phospho-tau ${ }_{181}$ and $\beta$-amyloid $(\mathrm{A} \beta)_{1-42}$ levels were determined using established ELISA methods $(17,18)$. Neuropathological post-mortem examinations were performed on 82 AD patients $(79 \pm 7.9$ years) and 100 controls $(77 \pm 9.4$ years). Consequently, data on the amounts of senile plaques (SPs) and NFTs were available. 
Individuals included in the study were recruited at the Clinical Memory Research Unit, Department of Clinical Sciences Malmö, Lund University, Sweden, and at the Neurotec Department, Section of Clinical Geriatrics, Karolinska Institutet, Karolinska University Hospital in Huddinge, Stockholm, Sweden. The study was approved by the local ethics committees in Sweden. The patients (or their closest relatives) and the control subjects gave their informed consent to participate in the study, which was conducted in accordance with the provisions of the Helsinki Declaration.

Patients in the clinical group were clinically diagnosed with probable late-onset AD according to the NINCDSADRDA criteria (19). Clinical diagnoses included a medical history, physical, neurological and psychiatric examination, screening laboratory tests, ECG, X-ray of the chest, EEG, and computerized tomography of the brain. The Mini-Mental State Examination (MMSE) was performed according to standard procedures (20). No patient had a family history of autosomal dominant dementia. In the clinical control group, only individuals without history, symptoms or signs of psychiatric or neurological disease, malignant disease, or systemic disorders were included. Individuals with MMSE scores below 28 were not recruited to the control group. In the post-mortem group, AD patients were clinically diagnosed with probable late-onset AD according to the NINCDS-ADRDA criteria (19), and were confirmed as definitive AD if the neuropathological diagnoses fulfilled the neuropathological CERAD criteria (21). All AD brains had a histopathological score of $>5$ and revealed no infarcts or other changes that could account for the dementia. Included in the neuropathological control group were individuals who had succumbed to cardiac or malignant disease. They had no history of dementia, psychiatric or neurological disease, and all brains had a histopathological score (22) of $\leq 4$. Clinical and post-mortem diagnoses were made without knowledge of the results of the biochemical and/or genetic analyses, and vice versa.

Genetic analysis. Gene designations follow the recommendations of the HUGO Gene Nomenclature Committee (23).

Genomic DNA was extracted from whole blood samples or brain tissue using the GenoPrep ${ }^{\mathrm{TM}}$ DNA Blood kit or DNA MagAttract kit (Qiagen, Hilden, Germany) together with the GenoM-48 Robotic Workstation (GenoVision, Oslo, Norway). Approximately $100 \mu \mathrm{l}$ of whole blood or $10 \mathrm{mg}$ of brain tissue was used for each extraction. The isolated genomic DNA was stored at $-20^{\circ} \mathrm{C}$ until it was used for gene analysis.

Primers surrounding the $C D K 5$ rs2069456 SNP were designed using the human $C D K 5$ genomic sequence information deposited in the UCSC database (http://genome.ucsc.edu). To diminish the risk of hairpin structures in the following Dynamic Allele Specific Hybridization (DASH) procedure, the PCR product was analysed with a DNA folding analysis program (MFOLD Zucker software). DASH probes matching the $\mathrm{A}$ and $\mathrm{C}$ variants of the PCR product were used. PCR was carried out using AmpliTaq Gold ${ }^{\circledR}$ (Applied Biosystems, Foster City, USA) in a final volume of $25 \mu$ l containing 5-20 ng of template DNA. The reaction was optimized by examining the size and specificity of the PCR product on a $2.5 \%$ agarose gel (SeaPlaque ${ }^{\circledR}$ GTG $^{\circledR}$ Agarose, FMC BioProducts, Philadelphia, USA). Optimal conditions were determined as:
$4.0 \mathrm{mM} \mathrm{MgCl} 2,200 \mu \mathrm{M}$ dNTPs, $0.5 \mathrm{U}$ of Taq, $0.36 \mathrm{pmol} /$ $\mu \mathrm{l}$ of the forward biotinylated primer (5'-Biotin-TCCGCTGTTACTCAGCTGAGG-3) and $0.44 \mathrm{pmol} / \mu \mathrm{l}$ of the reverse primer (5'-GACTCCCTCCCCCAATCCC-3'), (Invitrogen, Carlsbad, USA) in 1X PCR buffer. The thermal cycling profile was designed as follows: $10 \mathrm{~min}$ initial denaturation at $95^{\circ} \mathrm{C}$ followed by 40 cycles of $30 \mathrm{sec}$ at $95^{\circ} \mathrm{C}, 45 \mathrm{sec}$ at $59^{\circ} \mathrm{C}$, $1 \mathrm{~min}$ at $72^{\circ} \mathrm{C}$ and a final extension step of $10 \mathrm{~min}$ at $72^{\circ} \mathrm{C}$. Genotyping of the SNP was performed using the G-containing probe 5'-ATCCCATCGTCTAGCTC-Rox-3' (MWG Biotech, Ebersberg, Germany), as it gave the best separation of melting temperature. DASH procedure followed a previous description by Prince et al (24).

DNA sequencing was carried out for seven samples to confirm DASH genotyping. Amplification was performed using Taq DNA polymerase (Roche, Basel, Switzerland). Optimal conditions were $1.0 \mathrm{mM} \mathrm{MgCl}_{2}, 0.4 \mathrm{pmol} / \mu \mathrm{l}$ primers (forward: 5'-TTCAGAATGGGGAGCTGAAATTG-3'; reverse: 5'-ACTTAGAGGACTGGGGAGGAG-3' (Invitrogen), and $55^{\circ} \mathrm{C}$ hybridization temperature. In each reaction, 5-20 $\mathrm{ng}$ of template DNA was used. PCR products were purified using MicroSpin $^{\text {TM }}$ S-300 HR Columns (Amersham Biosciences, Piscataway, USA) and sequenced in both forward and reverse directions using cycle sequencing with fluorescent dNTPs (ABI PRISM Big Dye Terminator Cycle Sequencing Ready Reaction kit, Applied Biosystems), separation by capillary electrophoresis and detection by laser-induced fluorescence in an ABI PRISM 3100 Genetic Analyzer (Perkin-Elmer, Waltham, USA).

Apolipoprotein E (APOE) genotyping was performed using minisequencing as previously described (25). Two SNPs, rs7412 and rs429358, were used to determine the presence of the $\varepsilon 2, \varepsilon 3$ and $\varepsilon 4$ alleles.

Cerebrospinalfluid collection. In the AD patients and controls, CSF samples were obtained by lumbar puncture in the L3/L4 or L4/L5 interspaces under standardized conditions. A CSF volume of $12 \mathrm{ml}$ was collected and gently mixed to avoid gradient effects, followed by centrifugation to remove cell debris. CSF samples were collected according to standard conditions, then frozen and stored at $-80^{\circ} \mathrm{C}$ pending biochemical analysis without being refrozen. Details regarding CSF collection have previously been described (26).

Cerebrospinal fluid analysis. Levels of CSF total-tau (Innotest $^{\text {TM }}$ hTAU-Ag), phospho-tau [Innotest phospho$\operatorname{tau}(181 \mathrm{P})]$ and $\mathrm{A} \beta_{1-42}$ [Innotest $\beta$-amyloid(1-42)], all from Innogenetics (Gent, Belgium), were determined using a solid-phase enzyme immunoassay as previously described $(17,18,26,27)$. The detection limit for these assays on CSF samples is $20-50 \mathrm{pg} / \mathrm{ml}$. The analyses were run on the same batch of antibodies and ELISA plates. Day-to-day imprecision (CV) for all biochemical analyses was $<10 \%$.

Statistical analysis. CDK5 genotypes and allele frequencies comparing $\mathrm{AD}$ patients and control subjects were statistically analysed using Pearson's $\chi^{2}$ test. Testing for associations between genotypes andCSFbiomarkers (total-tau, phospho-tau, $\mathrm{A} \beta_{1-42}$, ) and histopathological scoring (SPs and NFTs) was performed using the analysis of variance (ANOVA). Since the 
Table I. CDK5 and APOE genotype and allele frequencies in Alzheimer's patients and controls.

\begin{tabular}{|c|c|c|c|c|c|c|c|c|c|c|c|c|}
\hline & \multicolumn{7}{|c|}{ Genotype frequencies } & \multicolumn{5}{|c|}{ Allele frequencies } \\
\hline & \multirow[b]{2}{*}{ No. } & \multicolumn{3}{|c|}{$C D K 5$} & \multicolumn{3}{|c|}{$A P O E$} & \multirow[b]{2}{*}{ No. } & \multicolumn{2}{|c|}{$C D K 5$} & \multicolumn{2}{|c|}{$A P O E$} \\
\hline & & $\mathrm{AA}(\%)$ & $\mathrm{AC}(\%)$ & $\mathrm{CC}(\%)$ & No $\varepsilon 4(\%)$ & One $\varepsilon 4(\%)$ & Two $\varepsilon 4(\%)$ & & $\mathrm{A}(\%)$ & $\mathrm{C}(\%)$ & $\varepsilon 2 / \varepsilon 3(\%)$ & $\varepsilon 4(\%)$ \\
\hline Patients & 347 & $170(49.0)$ & $151(43.5)$ & $26(7.5)$ & $96(27.7)$ & $179(51.6)$ & $72(20.7)^{\mathrm{a}}$ & 694 & 491 (70.7) & $203(29.3)$ & $371(53.5)$ & $323(46.5)^{\mathrm{a}}$ \\
\hline Controls & 157 & $82(52.2)$ & $61(38.9)$ & $14(8.9)$ & $112(71.3)$ & $41(26.1)$ & $4 \quad(2.6)$ & 314 & $225(71.7)$ & $89(28.3)$ & $265(84.4)$ & 49 (15.6) \\
\hline
\end{tabular}

$C D K 5$, cyclin-dependent kinase 5; APOE, apolipoprotein E; No., number of individuals. ${ }^{\text {a }} \mathrm{p}<0.001$ compared to controls, Pearson's $\chi^{2}$ test.

Table II. Cerebrospinal fluid protein levels in Alzheimer's disease patients and controls.

\begin{tabular}{lccc}
\hline CSF protein & Patients $(\mathrm{n}=265)$ & Controls $(\mathrm{n}=53)$ & P-value \\
\hline Total-tau & $670.4 \pm 21.2$ & $335.9 \pm 18.0$ & $\mathrm{P}<0.001$ \\
Phospho-tau & $84.3 \pm 2.1$ & $61.2 \pm 3.1$ & $\mathrm{P}<0.001$ \\
${\text { - } \text { - }_{\text {myloid }} \text {-42 }}_{1-1}$ & $479.0 \pm 6.8$ & $738.0 \pm 23.7$ & $\mathrm{P}<0.001$
\end{tabular}

CSF, cerebrospinal fluid. Data are the mean values $(\mathrm{pg} / \mathrm{ml}) \pm \mathrm{SEM}$; CSF protein levels between Alzheimer's disease patients and controls were compared using Kruskal-Wallis one-way analysis of variance.

CSF protein levels were slightly skewed, we also performed the non-parametric Kruskal-Wallis analysis of rank. Comparing observed and expected genotype frequencies using the $\chi^{2}$ test assessed deviations from Hardy-Weinberg equilibrium. All analyses were performed using the SYSTAT program version 10.2 (SYSTAT Software GmbH, Erkrath, Germany). P-values $<0.05$ was considered statistically significant.

\section{Results}

This study was well powered ( $>95 \%$ ) to significantly detect a minor allele resulting in a relative risk $>2$. Genotype frequencies conformed to Hardy-Weinberg equilibrium in both AD patients and control subjects. We verified the well-established association between the APOE genotype and AD (Table I). The $A P O E$ \& 4 allele was significantly more frequent in $\mathrm{AD}$ patients compared to control subjects (Table I).

Frequencies of the CDK5 genotype $(\mathrm{p}=0.54)$ or allele $(\mathrm{p}=0.68)$ did not differ between AD patients and control subjects (Table I). CDK5 genotype and allele frequencies were almost identical in the clinical $(\mathrm{p}=0.17, \mathrm{p}=0.50)$ and the postmortem $(\mathrm{p}=0.57, \mathrm{p}=0.42)$ populations (data not shown).

Comparisons of CSF biomarkers in AD patients and control subjects have previously revealed highly significant differences (28). As expected, we found that the AD patients had increased levels of total-tau and phospho-tau and decreased levels of $\mathrm{A} \beta_{1-42}$ in CSF compared to the control group (Table II). When analyzing the results for a possible association between $C D K 5$ gene variants and levels of CSF biomarkers, no such association was found (Table III). Neither total-tau ( $\mathrm{p}=0.62)$, phospho-tau $(\mathrm{p}=0.66)$ nor $\mathrm{A} \beta_{1-42}(\mathrm{p}=0.34) \mathrm{CSF}$ levels were influenced by the $C D K 5$ SNP (Table III).
Table III. Biochemical markers in cerebrospinal fluid and CDK5 genotypes in Alzheimer's disease patients and controls.

\begin{tabular}{|c|c|c|c|}
\hline CSF protein & AA & $\mathrm{AC}$ & $\mathrm{CC}$ \\
\hline Patients (no.) & 132 & 111 & 22 \\
\hline Total-tau & $682.2 \pm 32.1$ & $632.8 \pm 28.7$ & $789.3 \pm 79.6$ \\
\hline Phospho-tau & $86.1 \pm 3.3$ & $80.5 \pm 2.9$ & $92.4 \pm 6.2)$ \\
\hline$\beta$-amyloid ${ }_{1-42}$ & $468.5 \pm 9.6$ & $492.2 \pm 10.5^{\mathrm{a}}$ & $475.9 \pm 23.2$ \\
\hline Controls (no.) & 27 & 17 & 9 \\
\hline Total-tau & $332.8 \pm 25.6$ & $345.6 \pm 30.9$ & $326.7 \pm 49.0$ \\
\hline Phospho-tau & $58.9 \pm 4.6$ & $64.7 \pm 5.0$ & $61.3 \pm 8.3$ \\
\hline$\beta$-amyloid am-42 $_{1}$ & $746.4 \pm 33.6$ & $708.9 \pm 44.0$ & $767.4 \pm 53.8$ \\
\hline
\end{tabular}

CSF, cerebrospinal fluid. Data are the mean values $(\mathrm{pg} / \mathrm{ml}) \pm \mathrm{SEM}$. ${ }^{a}$ Evaluated in 110 patients only.

As expected, the histopathological scores of SPs and NFTs were significantly higher in AD patients compared to control subjects $(\mathrm{p}<0.001)$. However, no correlation was found between SP-NFT scores and CDK5 genotypes $(\mathrm{p}=0.18$, data not shown).

We also explored whether the results were influenced by $A P O E$ status. CDK5 genotype and allele frequencies did not differ in $\mathrm{AD}$ patients with different numbers of $A P O E \varepsilon 4$ alleles (data not shown).

\section{Discussion}

Several genetic association studies have previously been performed for $\mathrm{AD}$ (29). To date, the $\varepsilon 4$ variant of the $A P O E$ gene is the best established risk gene for $\operatorname{AD}(30,31)$.

In the present study, we investigated a CDK5 SNP (rs2069456) with a relatively high population frequency (http://genome.ucsc.edu) and examined whether it was associated with an increased risk of AD. Since we had access to CSF samples and brain tissue from subsets of the participants, CDK5 gene data was examined in relation to biochemical and neuropathological markers for AD.

We considered $C D K 5$ to be a good candidate gene for study, since accumulating evidence indicates that the cdk5 protein participates in several AD-associated events. Cdk5 has been found to be involved in AD-specific tau hyperphosphorylation, and interacts closely with the NFTs $(8,12,13)$. Cdk5 is predomi- 
nantly expressed in brain tissue, and elevated Cdk5 activity is evident in brain tissue from AD patients $(10,14)$. Interestingly, the evidence suggests that cdk5 is a key player linking $A \beta$ toxicity to tau pathology and neurodegeneration. $A \beta$ treatment has been found to transform cdk5 into a hyperactive kinase through its activators, p25 or p29 (32). Accumulation of p25 is found in human AD brains (33), and cdk5 closely interacts with NFTs (12).

Despite the high power of the present study, the CDK5 SNP did not influence AD risk, neither in the whole population, nor in subsets of samples. The results were not affected following $A P O E \& 4$ stratification of AD patients. CDK5 gene variants had no effect on CSF biomarkers or neuropathological scores for $\mathrm{AD}$. In conclusion, we found no evidence indicating that the $C D K 5$ gene significantly contributes to the pathogenesis of AD.

\section{References}

1. Lee VM, Goedert M and Trojanowski JQ: Neurodegenerative tauopathies. Annu Rev Neurosci 24: 1121-1159, 2001.

2. Blennow K, De Leon MJ and Zetterberg H: Alzheimer's disease. Lancet 368: 387-403, 2006.

3. Buee L, Bussiere T, Buee-Scherrer V, Delacourte A and Hof PR: Tau protein isoforms, phosphorylation and role in neurodegenerative disorders. Brain Res Brain Res Rev 33: 95-130, 2000.

4. Hanger DP, Mann DM, Neary D and Anderton BH: Molecular pathology of Alzheimer's disease in sporadic and familial Alzheimer's disease with mutations in the amyloid precursor protein. Biochem Soc Trans 20: 642-645, 1992.

5. Ishiguro K, Takamatsu M, Tomizawa K, et al: Tau protein kinase I converts normal tau protein into A68-like component of paired helical filaments. J Biol Chem 267: 10897-10901, 1992.

6. Mandelkow EM, Drewes G, Biernat J, et al: Glycogen synthase kinase-3 and the Alzheimer-like state of microtubule-associated protein tau. FEBS Lett 314: 315-321, 1992.

7. Paudel HK, Lew J, Ali Z and Wang JH: Brain proline-directed protein kinase phosphorylates tau on sites that are abnormally phosphorylated in tau associated with Alzheimer's paired helical filaments. J Biol Chem 268: 23512-23518, 1993.

8. Baumann K, Mandelkow EM, Biernat J, Piwnica-Worms H and Mandelkow E: Abnormal Alzheimer-like phosphorylation of tauprotein by cyclin-dependent kinases cdk2 and cdk5. FEBS Lett 336: 417-424, 1993.

9. Nguyen MD, Mushynski WE and Julien JP: Cycling at the interface between neurodevelopment and neurodegeneration. Cell Death Differ 9: 1294-1306, 2002.

10. Tang D, Yeung J, Lee KY, et al: An isoform of the neuronal cyclin-dependent kinase 5 (Cdk5) activator. J Biol Chem 270: 26897-26903, 1995.

11. Dhavan R and Tsai LH: A decade of CDK5. Nat Rev Mol Cell Biol 2: 749-759, 2001.

12. Augustinack JC, Sanders JL, Tsai LH and Hyman BT: Colocalization and fluorescence resonance energy transfer between cdk5 and AT8 suggests a close association in preneurofibrillary tangles and neurofibrillary tangles. J Neuropathol Exp Neurol 61: 557-564, 2002.

13. Liu WK, Williams RT, Hall FL, Dickson DW and Yen SH: Detection of a Cdc2-related kinase associated with Alzheimer paired helical filaments. Am J Pathol 146: 228-238, 1995.

14. Lee KY, Clark AW, Rosales JL, Chapman K, Fung T and Johnston RN: Elevated neuronal Cdc2-like kinase activity in the Alzheimer disease brain. Neurosci Res 34: 21-29, 1999.
15. Patrick GN, Zukerberg L, Nikolic M, De la Monte S, Dikkes P and Tsai LH: Conversion of $\mathrm{p} 35$ to $\mathrm{p} 25$ deregulates Cdk5 activity and promotes neurodegeneration. Nature 402: 615-622, 1999.

16. Grynspan F, Griffin WR, Cataldo A, Katayama S and Nixon RA: Active site-directed antibodies identify calpain II as an earlyappearing and pervasive component of neurofibrillary pathology in Alzheimer's disease. Brain Res 763: 145-158, 1997.

17. Blennow K, Wallin A, Agren H, Spenger C, Siegfried J and Vanmechelen E: Tau protein in cerebrospinal fluid: a biochemical marker for axonal degeneration in Alzheimer disease? Mol Chem Neuropathol 26: 231-245, 1995.

18. Vanderstichele H, van KerschaverE,Hesse C, et al: Standardization of measurement of beta-amyloid(1-42) in cerebrospinal fluid and plasma. Amyloid 7: 245-258, 2000.

19. McKhann G, Drachman D, Folstein M, Katzman R, Price D and Stadlan EM: Clinical diagnosis of Alzheimer's disease: report of the NINCDS-ADRDA Work Group under the auspices of Department of Health and Human Services Task Force on Alzheimer's Disease. Neurology 34: 939-944, 1984.

20. Folstein MF, Folstein SE and McHugh PR: 'Mini-mental state'. A practical method for grading the cognitive state of patients for the clinician. J Psychiatr Res 12: 189-198, 1975.

21. Mirra SS, Heyman A, McKeel D, et al: The Consortium to Establish a Registry for Alzheimer's Disease (CERAD). Part II. Standardization of the neuropathologic assessment of Alzheimer's disease. Neurology 41: 479-486, 1991.

22. Alafuzoff I, Iqbal K, Friden H, Adolfsson R and Winblad B: Histopathological criteria for progressive dementia disorders: clinical-pathological correlation and classification by multivariate data analysis. Acta Neuropathol 74: 209-225, 1987.

23. Eyre TA, Ducluzeau F, Sneddon TP, Povey S, Bruford EA and Lush MJ: The HUGO Gene Nomenclature Database, 2006 updates. Nucleic Acids Res 34: D319-D321, 2006.

24. Prince JA, Feuk L, Howell WM, et al: Robust and accurate single nucleotide polymorphism genotyping by dynamic allele-specific hybridization (DASH): design criteria and assay validation. Genome Res 11: 152-162, 2001

25. Blennow K, Ricksten A, Prince JA, et al: No association between the alpha2-macroglobulin (A2M) deletion and Alzheimer's disease, and no change in A2M mRNA, protein, or protein expression. J Neural Transm 107: 1065-1079, 2000.

26. Andreasen N, Hesse C, Davidsson P, et al: Cerebrospinal fluid beta-amyloid(1-42) in Alzheimer disease: differences between early- and late-onset Alzheimer disease and stability during the course of disease. Arch Neurol 56: 673-680, 1999.

27. Vanmechelen E, Vanderstichele H, Davidsson $\mathrm{P}$, et al: Quantification of tau phosphorylated at threonine 181 in human cerebrospinal fluid: a sandwich ELISA with a synthetic phosphopeptide for standardization. Neurosci Lett 285: 49-52, 2000.

28. Andreasen N, Minthon L, Davidsson P, et al: Evaluation of CSF-tau and CSF-Abeta42 as diagnostic markers for Alzheimer disease in clinical practice. Arch Neurol 58: 373-379, 2001.

29. Bertram L and Tanzi RE: Alzheimer's disease: one disorder, too many genes? Hum Mol Genet 13 Spec No 1: R135-R141, 2004.

30. StrittmatterWJ, Saunders AM, Schmechel D, et al: Apolipoprotein E: high-avidity binding to beta-amyloid and increased frequency of type 4 allele in late-onset familial Alzheimer disease. Proc Natl Acad Sci USA 90: 1977-1981, 1993.

31. Poirier J, Davignon J, Bouthillier D, Kogan S, Bertrand P and Gauthier S: Apolipoprotein E polymorphism and Alzheimer's disease. Lancet 342: 697-699, 1993.

32. Cruz JC and Tsai LH: A Jekyll and Hyde kinase: roles for Cdk5 in brain development and disease. Curr Opin Neurobiol 14: 390-394, 2004.

33. Tseng HC, Zhou Y, Shen Y and Tsai LH: A survey of Cdk5 activator $\mathrm{p} 35$ and $\mathrm{p} 25$ levels in Alzheimer's disease brains. FEBS Lett 523: 58-62, 2002. 